\title{
Healthy China 2030: how to control the rising trend of unintentional suffocation death in children under five years old
}

\author{
Fanjuan Kong ${ }^{1}$, Lili Xiong ${ }^{1}$, Aihua Wang ${ }^{1}$, Donghua Xie ${ }^{1}$, Jian He${ }^{1}$, Jinping Su${ }^{1}$, Kui Wu ${ }^{2}$, Zhiyu Liu ${ }^{1 *+}$ and \\ Hua Wang ${ }^{3^{*}+}$
}

\begin{abstract}
Background: To investigate the occurrence frequency, changing trends, and epidemiological distribution of unintentional suffocation in children under 5 years old.

Methods: The data were collected from the Maternal and Child Health Surveillance system from 2009 to 2018. The cause of death was classified by ICD-10. Data on unintentional suffocation death were calculated according to the characteristics of the population, time, space, cause of death and medical treatment, and constituent ratio were calculated.

Results: The mortality rate of children under 5 years old showed a downward trend, but the mortality of unintentional suffocation initially decreased and then increased. The death rate of unintentional suffocation in children less than 1-yearold was much higher than that in children aged 1 to 4 years old. The death rate of unintentional suffocation was higher in boys than in girls, and the rate was higher for rural children than for urban children. The number of low-weight and pre-term infants in the group under 1-year-old was significantly higher than that in the group of 1-4 years old. Children under 1-year-old are more likely to die at home than children aged 1 to 4 years old, and a higher proportion of younger children did not receive treatment. More than $80 \%$ of children under the age of $5 \mathrm{go}$ untreated because it was too late to go to the hospital.
\end{abstract}

Conclusion: For areas and populations with a high incidence of unintentional suffocation, we suggest that priorities should include prevention, the development of a safe environment, strengthened prevention, the development of safety habits, and the popularization of first aid knowledge.

Keywords: Unintentional suffocation, Children under five years old, Children under 1 -year-old, Children aged 1 to 4 years, Death

\footnotetext{
*Correspondence: 327532957@qq.com; wanghua213@aliyun.com

†Z Zhiyu Liu and Hua Wang contributed equally to this work.

'Department of Information Management, Hunan Provincial Maternal and

Child Health Care Hospital, 53 Xiangchun Road, Changsha 410078, Hunan,

China

${ }^{3} \mathrm{NHC}$ Key Laboratory of Birth Defect for Research and Prevention, Hunan

Provincial Maternal and Child Health Care Hospital, 53 Xiangchun Road,

Changsha 410078, Hunan, China

Full list of author information is available at the end of the article
}

(c) The Author(s). 2020 Open Access This article is licensed under a Creative Commons Attribution 4.0 International License, which permits use, sharing, adaptation, distribution and reproduction in any medium or format, as long as you give appropriate credit to the original author(s) and the source, provide a link to the Creative Commons licence, and indicate if changes were made. The images or other third party material in this article are included in the article's Creative Commons licence, unless indicated otherwise in a credit line to the material. If material is not included in the article's Creative Commons licence and your intended use is not permitted by statutory regulation or exceeds the permitted use, you will need to obtain permission directly from the copyright holder. To view a copy of this licence, visit http://creativecommons.org/licenses/by/4.0/ The Creative Commons Public Domain Dedication waiver (http://creativecommons.org/publicdomain/zero/1.0/) applies to the data made available in this article, unless otherwise stated in a credit line to the data. 


\section{Background}

Child injury is a significant global public health problem, and more than $98 \%$ of child injury deaths occur in developing countries [1]. Injuries mainly include road traffic injuries, suicide, falls, and drowningdrowning [2]. Life expectancy in developing countries is reduced by 1.19 years due to injury [3]. In China [4], the proportion of injury deaths among $0-14$ years of children in China rose from $18.69 \%$ in 2004 to $21.26 \%$ in 2011 . Injury is also the leading cause of death among children aged 1 to 4 years old [2]. In China, $14.6 \%$ of deaths among children under 5 years of age are due to injuries [5].

Injuries, like diseases, can be recognized, prevented, and controlled [6-8]. The mortality rate of children under 5 years of age in China dropped from 61.0 per thousand in 1991 to 8.4 per thousand in 2018, a decrease of $86.2 \%$ [9]. Unintentional suffocation constitutes the most significant proportion of injury deaths among children under the age of 5 in China [9-11]. However, the current research focuses on either major-specific injuries, such as traffic accidents or drowning, or the entire age group of children. A previous study investigated under-five mortality from unintentional suffocation in the Chinese population from 2006 to 2016 and reported a total of 2937 cases from 161 surveillance points [12], which covered 161 surveillance points in China and included a sample size of 2937 cases. This study analyzed the incidence and causes of unintentional suffocation death and compared the death rates of different age groups, men and women, and urban and rural areas.

This present study covers all areas of Hunan Province from 2009 to 2018 for population-wide surveillance and includes a sample size of 4933. A critical supplement to previous research is to analyze the treatment and causes of death of children in different age groups. To reduce the unintentional suffocation mortality rate of children under 5 years old in the province and improve the health level of children in an attempt to truly implement the goal of "healthy China 2030" [13]. It is necessary to investigate and analyze the death situation and the changing trend of this part of the population.

\section{Method}

\section{Data source}

Hunan Province (Fig. 1.The URL is https://user.qzone. qq.com/327532957/infocenter) is located in the hinterland of southeast China and the middle reaches of the Yangtze River, which is the bridge between the eastern coastal provinces and the western inland provinces. The land area of the region is $211,800 \mathrm{~km}^{2}$, with mountains accounting for approximately half of the total area and plains, basins, hills, and water surfaces accounting for approximately half. The population of the province is approximately 73 million. The province has a mild climate and four distinct seasons, with sufficient heat and concentrated precipitation, changeable spring temperatures and

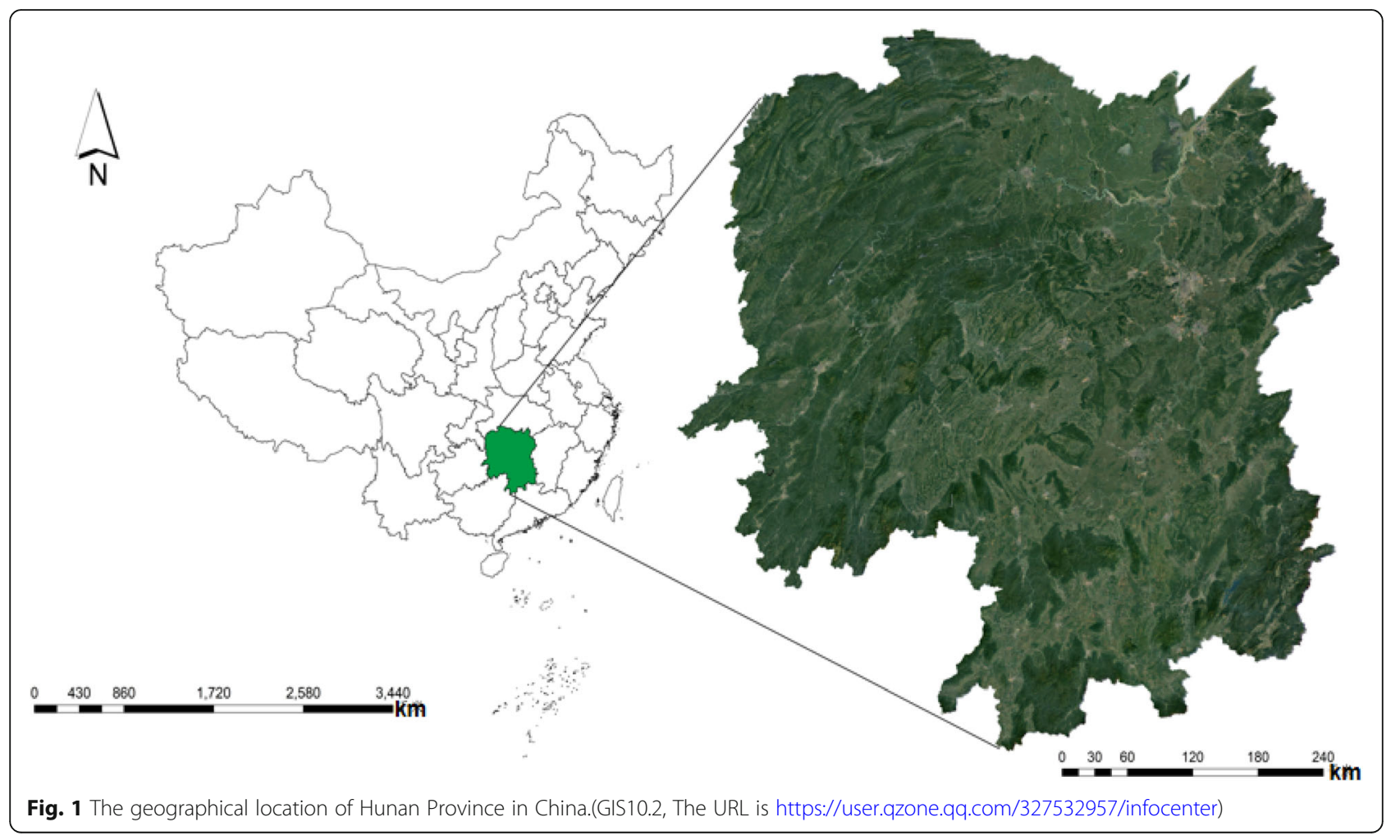


drought in summer and autumn, a short severe cold period, and a long summer heat period.

The cause of death data comes from the maternal and child health surveillance system, which covers all the data on accidental injury deaths in Hunan Province and conducts the total population surveillance. The Chinese death Surveillance Program for Children under 5 requires that the root causes of deaths of children under 5 be coded according to the International Classification of Diseases (ICD-10). Between 2009 and 2018, a total of 59, 880 children under 5 years of age died and 4933 cases of unintentional suffocation were identified. Unintentional suffocation refers to hypoxia and asphyxia caused by accidental causes, such as the baby being covered by a quilt, mother turning over and accidentally crushing to death, mother's nipple blockage, and foreign body in the trachea.

China has established a child death reporting network and corresponding monitoring system centered on maternal and child health care institutions, with special personnel at all levels responsible for the collection, collation and preservation of data. All deaths are required to fill in the "Child death report Card" and use paper reports and direct network reports in parallel.

\section{Quality control}

Child death information is reported, verified and collected step by step by the village and township health center, the district and county maternal and child health institutions, the municipal maternal and child health hospital, the provincial maternal and child health hospital, the China Disease Prevention and Control Center and the Maternal and Child Health Center. All levels check the logic, completeness, and correctness of the collected child death report cards. Random spot checks are conducted annually by the state at the provincial level, twice a year at the municipal level, and once a quarter at the district and county levels. Child death information from family planning, public security, civil affairs, disease control and control departments ("National Population and Death Information Registration and Management system") and medical institutions is checked and supplemented.

\section{Data reporting method}

The death information was reported through the Hunan Maternal and Child Health Surveillance Information system according to the requirements of the China Maternal and Child Health Surveillance Information system.

\section{Statistical methods}

The fundamental cause of death was judged, coded and classified by ICD-10, and the data on the cause of death was analyzed by total mortality, disease-specific mortality, age-specific mortality and the composition of death causes and statistically analyzed using the SPSS17.0 software package. The primary statistical analysis methods were the chi-square test and chi-square trend test. We used GIS10.2 software to make a map of Hunan Province.

\section{Results}

From 2009 to 2018, the maternal and child health surveillance system showed that there were 7,942,123 live births, 59,880 deaths of children under 5 years old, and 4933 children died of unintentional suffocation. The mortality rate of children under 5 years old showed a downward trend from $10.9 \%$ in 2009 to $5.3 \%$ in 2018 , decreased by $51.4 \%$.The death rate of unintentional suffocation in children under 5 years old decreased from $90.8 / 100000$ in 2009 to $45.4 / 10000$ in 2017 , decreased by $50 \%$.But the death rate of unintentional suffocation in 2018 was higher than that in previous years. There were significant differences in child mortality and unintentional suffocation mortality over the years $(\mathrm{P}<0.001)$. The proportion of unintentional suffocation deaths in the number of children under the age of 5 showed a fluctuating upward trend from $8.4 \%$ in 2009 to $11.7 \%$ in 2018, increased by $28.2 \%$ Table 1 .

The number of unintentional suffocation deaths among children under 5 years old was 4933, of which 4109 (83.3\%) were under 1-year-old and 824 (16.7\%) were 1-4 years old. The unintentional suffocation mortality rate of children under 1-year-old decreased from 77.5/100000 in 2009 to $50.2 / 100000$ in 2018 , decreased by $35.2 \%$. The mortality rate of unintentional suffocation in children aged 1 to 4 years fluctuated around 10/100000. The mortality rate of unintentional suffocation in children under 1 -year-old was significantly higher than that in children aged 1-4 years old, which was about 5 times higher than that in children aged 1-4 years old. As shown in Table 2 and Fig. 2.

For infants under1-year-old, the mortality rate of unintentional suffocation was 55.7/100000 in rural areas and $44.2 / 100000$ in urban areas. The death rate of unintentional suffocation was 55.1/100000 in boys and 47.6/ 100000 in girls. For children aged 1-4 years old, the mortality rate of unintentional suffocation was 10.5/ 100000 in rural areas and 9.6/100000 in urban areas. The death rate of unintentional suffocation was 12.8/ 100000 in boys and 7.6/100000 in girls. The infants under 1-year-old in urban and rural areas and males and females were higher than those in 1-4 years old group $(P<0.001)$. As shown in Table 3.

There were 2826 cases $(68.7 \%)$ of infants under 1year-old in the first and fourth quarters, 361 cases $(8.8 \%)$ of low birth weight infants and 287 cases $(7.0 \%)$ of premature infants. 1906 (46.4\%) died at home, 614 (12.1\%) died on the way to the hospital, 2942 (71.6\%) did not 
Table 1 Death and unintentional suffocation of children under five years of age from 2009 to 2018

\begin{tabular}{|c|c|c|c|c|c|c|}
\hline \multirow[t]{2}{*}{ Year } & \multirow{2}{*}{$\begin{array}{l}\text { Number } \\
\text { of live births }\end{array}$} & \multicolumn{2}{|c|}{ Children under 5 years old } & \multicolumn{2}{|c|}{ Unintentional suffocation } & \multirow{2}{*}{$\begin{array}{l}\text { Percentage of deaths } \\
\text { in children under } \\
5 \text { years of age }(\%)\end{array}$} \\
\hline & & $\mathrm{N}$ & Mortality Rate (per 1000 persons) & $\mathrm{N}$ & Mortality Rate (per 100,000 persons) & \\
\hline 2009 & 781,026 & 8482 & 10.9 & 709 & 90.8 & 8.4 \\
\hline 2010 & 797,902 & 8636 & 10.8 & 584 & 73.2 & 6.8 \\
\hline 2011 & 805,360 & 7509 & 9.3 & 586 & 72.8 & 7.8 \\
\hline 2012 & 838,974 & 7343 & 8.8 & 642 & 76.5 & 8.7 \\
\hline 2013 & 821,345 & 5747 & 7.0 & 466 & 56.7 & 8.1 \\
\hline 2014 & 780,572 & 5087 & 6.5 & 316 & 40.5 & 6.2 \\
\hline 2015 & 781,066 & 4791 & 6.1 & 404 & 51.7 & 8.4 \\
\hline 2016 & 795,399 & 4435 & 5.6 & 405 & 50.9 & 9.1 \\
\hline 2017 & 834,955 & 4084 & 4.9 & 379 & 45.4 & 9.3 \\
\hline 2018 & 705,524 & 3766 & 5.3 & 442 & 62.6 & 11.7 \\
\hline Total & $7,942,123$ & 59,880 & 7.5 & 4933 & 62.1 & 8.2 \\
\hline$x^{2}$ & & 4729.54 & & 291.50 & & \\
\hline $\mathbf{P}$ & & $<0.001$ & & $<0.00$ & & \\
\hline
\end{tabular}

receive treatment, $2406(81.8 \%)$ had no time to go to the hospital, and $65.2 \%$ of the deaths were postmortem. Most of the children aged 1 to 4 are full-term and normal-weight babies. Two hundred forty-five children (29.7\%) died at home, 204 children (24.8\%) died on their way to the hospital, and 510 children $(61.9 \%)$ did not receive treatment because 430 children $(84.3 \%)$ did not have time to go to the hospital. $54.4 \%$ of deaths were inferred postmortem. As shown in Table 4.

\section{Discussion}

The main results are as follows. (1) The mortality rate of children under 5 years old showed a downward trend, but the death rate of unintentional suffocation showed an upward trend, and the proportion of unintentional suffocation death in children under 5 years old also increased. (2) The unintentional suffocation mortality rate of children under 1-year-old (51.7/100000) was much higher than that of 4-year-old children (10.4/100000). Children under 1-year-old were more likely to die at home from unintentional suffocation than children aged 5 years old, and more of the younger children did not receive treatment. (3) The unintentional suffocation mortality rate of boys and children in rural areas was higher than that of girls and children in urban areas.

The death rate of unintentional suffocation has changed from a decline to an upward trend, which is consistent with the direction of the United States [14]. The proportion of unintentional suffocation deaths to the

Table 2 Unintentional suffocation deaths of children less than 1 year old and children aged 1 to 4 years old

\begin{tabular}{|c|c|c|c|c|c|c|c|c|}
\hline \multirow[t]{2}{*}{ Year } & \multirow{2}{*}{$\begin{array}{l}\text { Number } \\
\text { of infant } \\
\text { deaths }\end{array}$} & \multicolumn{3}{|c|}{ Unintentional suffocation of infants under 1 year old } & \multirow{2}{*}{$\begin{array}{l}\text { Number of deaths } \\
\text { of children aged } \\
1 \text { to } 4 \text { years old }\end{array}$} & \multicolumn{3}{|c|}{ Unintentional suffocation in children aged 1 to 4 years old } \\
\hline & & $\bar{N}$ & $\begin{array}{l}\text { Mortality rate } \\
\text { (per 100,000 persons) }\end{array}$ & $\begin{array}{l}\text { Percentage of } \\
\text { infant deaths (\%) }\end{array}$ & & $\bar{N}$ & $\begin{array}{l}\text { Mortality Rate } \\
\text { (per 100,000 persons) }\end{array}$ & $\begin{array}{l}\text { Percentage of deaths among } \\
\text { children aged } 1 \text { to } 4 \text { years old }\end{array}$ \\
\hline 2009 & 6058 & 605 & 77.5 & 10.0 & 2424 & 104 & 13.3 & 4.29 \\
\hline 2010 & 5868 & 488 & 61.2 & 8.3 & 2768 & 96 & 12 & 3.47 \\
\hline 2011 & 5138 & 501 & 62.2 & 9.8 & 2371 & 85 & 10.6 & 3.58 \\
\hline 2012 & 4803 & 538 & 64.1 & 11.2 & 2540 & 104 & 12.4 & 4.09 \\
\hline 2013 & 3851 & 401 & 48.8 & 10.4 & 1896 & 65 & 7.9 & 3.43 \\
\hline 2014 & 3277 & 257 & 32.9 & 7.8 & 1810 & 59 & 7.6 & 3.26 \\
\hline 2015 & 3117 & 333 & 42.6 & 10.7 & 1674 & 71 & 9.1 & 4.24 \\
\hline 2016 & 2825 & 329 & 41.4 & 11.6 & 1610 & 76 & 9.6 & 4.72 \\
\hline 2017 & 2592 & 303 & 36.3 & 11.7 & 1492 & 76 & 9.1 & 5.09 \\
\hline 2018 & 2367 & 354 & 50.2 & 15.0 & 1399 & 88 & 12.5 & 6.29 \\
\hline Total & 39,896 & 4109 & 51.7 & 10.3 & 19,984 & 824 & 10.4 & 4.12 \\
\hline
\end{tabular}




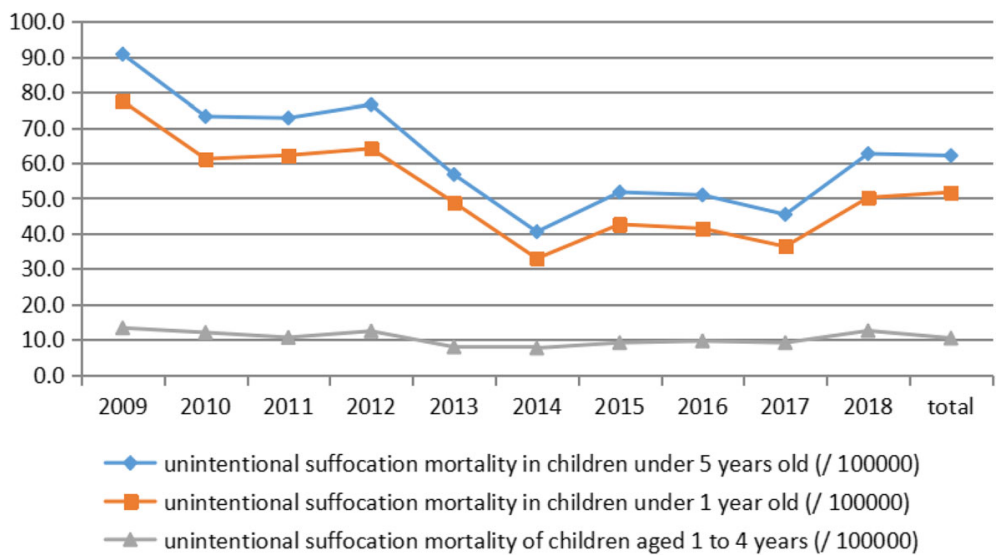

Fig. 2 Comparison of unintentional suffocation mortality among children of different age groups

number of children under 5 years old is also on the rise, which is consistent with a national study [10]. Most unintentional suffocation deaths $(83.3 \%)$ were children under 1-year-old, which is consistent with reports from China [12], the United States [15], Canada [16] and Japan [17]. Children younger than 1-year-old cannot yet walk, and their injuries are mainly due to the negligence or abuse of their parents, while children aged 1-4 years old demonstrate hyperactivity, curiosity and exploration, resulting in many injuries to themselves [18].

The unintentional suffocation mortality rate of boys and rural children is higher than that of girls and urban children, which is consistent with previous studies [12, 19, 20]. Especially among children over 1 -year-old, boys tend to be more impulsive and active and engage in riskier behaviors than girls [21]. The frequency of child injuries in underdeveloped communities in Pakistan is three times higher than that in developed cities [22]. The difference in injuries between rural and urban areas of China increases significantly with time [23], which may be related to the living environment, health awareness, medical facilities and inconvenient transportation in underdeveloped rural areas. In 2019, a total of 17.787 million migrant workers in Hunan left (https://www.anhui365.net/PostCenter/ThreadDetail/id/8761234) and approximately 700,000 children stayed at home with their grandparents [24], which may lead to inadequate care of these left-behind children. The study [25] have shown that the childhood injury rate of left-behind children in rural areas (33.5\%) is significantly higher than that of non-left-behind children (28.6\%).

The situation for children who die of unintentional suffocation is not optimistic. In the first and fourth quarters, the number of unintentional suffocation deaths was higher than that in the second and third quarters, which may be related to lower temperatures in the first and fourth quarters, thicker quilts for sleeping at night and being pinned down when sleeping with parents. Low weight and non-term infants were concentrated in children under 1-year-old, which may be related to immature organs, imperfect sucking and swallowing function, small stomach capacity, lack of digestive enzymes, poor absorption and digestion ability, and so on. Nearly $50 \%$ of children under the age of one died at home, $24.8 \%$ of children aged 1 to 4 died on their way to the hospital, and more than $80 \%$ of the children did not see a doctor because they did not have time to go to the hospital. This situation may be related to the rapid occurrence of unintentional suffocation and the short time of death. There are many rural and mountainous areas in Hunan Province, and the accessibility of medical services needs to be improved. The prevention of unintentional suffocation is the fundamental measure. Many parents do not know how to provide first aid on the

Table 3 Comparison of the incidence of Unintentional suffocation between urban and rural areas and between men and women

\begin{tabular}{|c|c|c|c|c|c|c|c|}
\hline \multirow[t]{2}{*}{ Indicators } & \multirow{2}{*}{$\begin{array}{l}\text { Number } \\
\text { of live } \\
\text { births }^{\mathrm{a}}\end{array}$} & \multicolumn{2}{|c|}{$<1$ year old } & \multicolumn{2}{|c|}{$1-4$ years old } & \multirow[t]{2}{*}{$x^{2}$} & \multirow[t]{2}{*}{$P$} \\
\hline & & $\mathrm{N}$ & Mortality rate (per 100,000 persons) & $\mathrm{N}$ & Mortality rate (per 100,000 persons) & & \\
\hline Rural & $5,220,568$ & 2906 & 55.7 & 550 & 10.5 & 1606.648 & $<0.001$ \\
\hline Urban & $2,721,400$ & 1203 & 44.2 & 262 & 9.6 & 604.587 & $<0.001$ \\
\hline Male & $4,232,951$ & 2331 & 55.1 & 541 & 12.8 & 1116.02 & $<0.001$ \\
\hline Female & $3,709,017$ & 1766 & 47.6 & 281 & 7.6 & 1077.593 & $<0.001$ \\
\hline
\end{tabular}

${ }^{\mathrm{a}}$ There were 155 cases of lack of live birth information 
Table 4 Comparison of the basic situation and treatment of unintentional suffocation between children less than 1 year old and children aged 1 to 4 years old

\begin{tabular}{|c|c|c|c|c|c|c|}
\hline \multirow[t]{2}{*}{ Indicators } & \multicolumn{2}{|c|}{$<1$ year old } & \multicolumn{2}{|c|}{$1-4$ years old } & \multirow[t]{2}{*}{$x^{2}$} & \multirow[t]{2}{*}{$P$} \\
\hline & $\mathrm{N}$ & Proportion(\%) & $\mathrm{N}$ & Proportion(\%) & & \\
\hline \multicolumn{7}{|l|}{ 1. Gender } \\
\hline Male & 2331 & 56.7 & 541 & 65.7 & \multirow[t]{3}{*}{22.486} & \multirow[t]{3}{*}{$<0.001$} \\
\hline Female & 1766 & 43.0 & 281 & 34.1 & & \\
\hline Missing & 12 & 0.3 & 2 & 0.2 & & \\
\hline \multicolumn{7}{|l|}{ 2. Urban and rural areas } \\
\hline Rural & 2906 & 70.7 & 550 & 66.7 & \multirow[t]{3}{*}{62.854} & \multirow[t]{3}{*}{$<0.001$} \\
\hline Urban & 1203 & 29.3 & 262 & 31.8 & & \\
\hline Missing & 0 & 0 & 12 & 1.5 & & \\
\hline \multicolumn{7}{|l|}{ 3. Quarter of death } \\
\hline First quarter & 1037 & 25.2 & 275 & 33.4 & \multirow[t]{4}{*}{122.605} & \multirow[t]{4}{*}{$<0.001$} \\
\hline Second quarter & 541 & 13.2 & 199 & 24.2 & & \\
\hline Third quarter & 742 & 18.1 & 131 & 15.8 & & \\
\hline Fourth quarter & 1789 & 43.5 & 219 & 26.6 & & \\
\hline \multicolumn{7}{|l|}{ 4. Household registration } \\
\hline Local household registration & 4019 & 97.8 & 820 & 99.5 & \multirow[t]{3}{*}{10.818} & \multirow[t]{3}{*}{0.004} \\
\hline Non-local household registration & 80 & 2 & 4 & 0.5 & & \\
\hline Missing & 10 & 0.2 & 0 & 0.0 & & \\
\hline \multicolumn{7}{|l|}{ 5. Birth weight } \\
\hline$<2500 \mathrm{~g}$ & 361 & 8.8 & 3 & 0.4 & \multirow[t]{4}{*}{88.129} & \multirow[t]{4}{*}{$<0.001$} \\
\hline $2500 \mathrm{~g}-4000 \mathrm{~g}$ & 3635 & 88.4 & 816 & 99.0 & & \\
\hline$>4000 \mathrm{~g}$ & 56 & 1.4 & 1 & 0.1 & & \\
\hline Missing & 57 & 1.4 & 4 & 0.5 & & \\
\hline \multicolumn{7}{|l|}{ 6. Gestational age } \\
\hline$<37$ weeks & 287 & 7.0 & 2 & 0.2 & \multirow[t]{4}{*}{90.321} & \multirow[t]{4}{*}{$<0.001$} \\
\hline 37-40 weeks & 3583 & 87.2 & 811 & 98.4 & & \\
\hline$>40$ weeks & 176 & 4.3 & 7 & 0.8 & & \\
\hline Missing & 63 & 1.5 & 4 & 0.6 & & \\
\hline \multicolumn{7}{|l|}{ 7. Place of death } \\
\hline Hospital & 867 & 21.1 & 224 & 27.2 & 181.765 & $<0.001$ \\
\hline On the way to see a doctor & 499 & 12.1 & 204 & 24.8 & & \\
\hline On the way home after transfer or treatment & 614 & 14.9 & 146 & 17.7 & & \\
\hline Home & 1906 & 46.4 & 245 & 29.7 & & \\
\hline Missing & 223 & 5.5 & 5 & 0.6 & & \\
\hline 8. Antemortem treatment & & & & & & \\
\hline Hospitalization & 502 & 12.2 & 94 & 11.4 & 252.243 & $<0.001$ \\
\hline Outpatient & 326 & 7.9 & 210 & 25.5 & & \\
\hline Untreated & 2942 & 71.6 & 510 & 61.9 & & \\
\hline Missing & 339 & 8.3 & 10 & 1.2 & & \\
\hline 9. Main reasons for not being treated or not & dical $t$ & nent & & & & \\
\hline Economic difficulties & 10 & 0.3 & 0 & 0 & 67.487 & $<0.001$ \\
\hline Traffic inconvenience & 22 & 0.8 & 4 & 0.8 & & \\
\hline Too late to take child to the hospital. & 2406 & 81.8 & 430 & 84.3 & & \\
\hline
\end{tabular}


Table 4 Comparison of the basic situation and treatment of unintentional suffocation between children less than 1 year old and children aged 1 to 4 years old (Continued)

\begin{tabular}{|c|c|c|c|c|c|c|}
\hline \multirow[t]{2}{*}{ Indicators } & \multicolumn{2}{|c|}{$<1$ year old } & \multicolumn{2}{|c|}{$1-4$ years old } & \multirow[t]{2}{*}{$x^{2}$} & \multirow[t]{2}{*}{$P$} \\
\hline & $\mathrm{N}$ & Proportion(\%) & $\mathrm{N}$ & Proportion(\%) & & \\
\hline Parents thought that the condition was not serious. & 31 & 1.1 & 2 & 0.4 & & \\
\hline Other & 114 & 3.9 & 12 & 2.4 & & \\
\hline Missing & 359 & 12.1 & 62 & 12.1 & & \\
\hline \multicolumn{7}{|l|}{ 10. Diagnostic basis of cause of death } \\
\hline Pathological autopsy & 11 & 0.3 & 5 & 0.6 & 38.556 & $<0.001$ \\
\hline Clinical & 1371 & 33.4 & 364 & 44.2 & & \\
\hline Postmortem inference & 2679 & 65.2 & 448 & 54.4 & & \\
\hline Missing & 48 & 1.1 & 7 & 0.8 & & \\
\hline
\end{tabular}

spot, and they often panic when their children have accidents and do not give first aid treatment [26]. In China, the lack of standardized procedures for emergency rescue often results in the inappropriate or incorrect medical treatment of trauma and failure to stabilize patients before hospital admission [27].

The United Nations has incorporated injury prevention into the Sustainable Development goals action plan [28]. In 2008, a study in the Lancet reported on "injuryrelated deaths in China, a public health problem that has not been fully recognized" [29]. In 2011, China issued the Program for the Development of Chinese Children (2011-2020) [30], which called for a nearly 17\% reduction in injury-related mortality among children under the age of 18. The outline of the Healthy China 2030 Plan [13] aims to establish a comprehensive injury monitoring system and formulate guidelines and standards for strengthening injury prevention and intervention, reducing traffic injuries and drowning, and preventing poisoning. These policies can play a specific role in reducing the occurrence of injuries. Nevertheless, the data from our province in the past 10 years show that the death rate of unintentional suffocation has an upward trend. Compared with developed countries such as the United States [31] and the United Kingdom [32], China lacks precise and specific action plans for child injury prevention.

The primary factor chain of an accidental injury is "no foresight consciousness-no preventive measures-no skill learning-no effective first aid". According to the incidence, individual characteristics, urban and rural distribution, cause analysis and treatment of accidental injury death, the following prevention and control measures are proposed.

First, safe feeding care should be provided. The critical issue is to improve the feeding and nursing of infants and young children to prevent the occurrence of unintentional suffocation. Guardians need to master correct nutritional knowledge (e.g., feeding posture, feeding volume), especially premature infants, low birth weight infants and other at-risk children. It is necessary to pay attention to sleep care (sleep posture, bedding thickness, and weight). Children aged 1 to 4 years old have a high risk of inhalation suffocation [12]. Attention should be paid to the inhalation of foreign bodies in the respiratory tract and the management of nuts, beans and buttons as dangerous substances to avoid exposure to young children.

The second proposal is to build a safe environment and strengthen the management of the children's living environment. Ribas Rde et al. [33] shows that the majority $(61.7 \%)$ of accidental injuries occur in or near the home, and appropriate preventive measures can reduce the risk by $26 \%$. Most unexplained infant deaths are potentially preventable and occur in highly dangerous sleep environments [34]. The safest way for infants to sleep is on their backs, on an unshared sleep surface, in a crib or bassinet in the caregivers' room, and without soft bedding (e.g., blankets, pillows, and other soft objects) in their sleep area [35].

The third suggestion is to popularize the knowledge of first aid. Because of the sudden and unpredictable nature of accidental death, the on-the-spot rescue of accidental death is very important. A useful primary aid measure is the last line of defense to reduce death or disability. The experience of first aid is widely publicized in a variety of ways, such as providing common first aid knowledge, such as emergency handling of foreign body inhalation and cardiopulmonary resuscitation, into brochures, children's songs, collective rap songs, dance, and demonstration videos. to improve caregivers' awareness of injuries and their ability to deal with emergencies. In particular, it is necessary to involve maternal and child health care institutions with Chinese characteristics and make use of the three-level network of child health care for publicity and education.

A few factors limited to this study. First, our questionnaire was a retrospective survey with retrospective bias. However, our inquiry was conducted as early as possible 
to minimize information bias, and data quality control was conducted at all levels of provinces, cities, and counties every year. Second, our questionnaire did not collect information about children's unintentional suffocation exposure, such as appropriate time, activity, and risk factors. We did not conduct a detailed analysis to credibly explain recent changes in mortality. Third, the contents of the unintentional suffocation death case card may be filled incorrectly or omitted. By setting logical detection and required options, and all levels of on-site quality control, our data quality has been guaranteed to a certain extent.

\section{Conclusion}

In conclusion, we report a decline in mortality among children under 5 years of age from 2009 to 2018, but unintentional suffocation deaths initially decreased and then increased. The unintentional suffocation mortality rate of infants under 1-year-old was 51.7/100000, which was much higher than that of children aged 1 to 4 years old (10.4/100000). The mortality rate of unintentional suffocation in boys and rural areas was higher than that in girls and urban regions. Infants under 1-year-old were more likely to die at home than children aged 1 to 4 years old, and a higher proportion of younger children did not receive treatment. Targeted prevention strategies should be adopted to advocate prevention, build a safe environment, strengthen safety prevention, develop safety habits, popularize first aid knowledge, and curb the rising trend of unintentional suffocation mortality.

\section{Acknowledgements}

We thank AJE (https://secure.aje.com) for editing this manuscript.

\section{Declarations}

The authors declare that they have no conflict of interests.

\section{Authors' contributions}

FK drafted the initial manuscript, and reviewed and revised the manuscript.AW, JH, LX, DX, JS and KW designed the data collection instruments, collected data, carried out the initial analyses, and reviewed and revised the manuscript. ZL and HW conceptualized and designed the study, coordinated and supervised data collection, and critically reviewed the manuscript for important intellectual content. All authors approved the final manuscript as submitted and agree to be accountable for all aspects of the work.

\section{Funding}

This study is not funded.

\section{Availability of data and materials}

No data are available. The cost estimates for this study were obtained under license and are not available for sharing.

Ethics approval and consent to participate

Not applicable.

\section{Consent for publication}

Written informed consent for publication was obtained from all participants.

\section{Competing interests}

All the authors have no conflicts of interest to disclose.

\section{Author details}

'Department of Information Management, Hunan Provincial Maternal and Child Health Care Hospital, 53 Xiangchun Road, Changsha 410078, Hunan, China. ${ }^{2}$ Department of Pediatrics, Hunan Provincial Maternal and Child Health Care Hospital, 53 Xiangchun Road, Changsha 410078, Hunan, China. ${ }^{3} \mathrm{NHC}$ Key Laboratory of Birth Defect for Research and Prevention, Hunan Provincial Maternal and Child Health Care Hospital, 53 Xiangchun Road, Changsha 410078, Hunan, China.

Received: 24 April 2020 Accepted: 7 August 2020

Published online: 13 August 2020

\section{References}

1. World Health Organization, UNICEF. World Report on Child Injury Prevention. Geneva: WHO; 2008.

2. Ozanne-Smith J, Li Q. A social change perspective on injury prevention in China. Inj Prev. 2018;0:1-7. https://doi.org/10.1136/injuryprev-2017-042712.

3. Fei F-R, Zhong J-M, Yu M, et al. Impact of injury-related mortality on life expectancy in Zhejiang, China based on death and population surveillance data. BMC Public Health. 2017;18(1). https://doi.org/10.1186/s12889-0174566-3.

4. Yin ZX, Wu J, Luo JS, et al. Burden and trend analysis of injury mortality in China among children aged 0-14 years from 2004 to 201l. BMJ Open. 2015; 5:I-7. https://doi.org/10.1136/bmjopen-2014-007307.1.

5. He C, Liu L, Chu Y, et al. National and subnational all-cause and causespecific child mortality in China, 1996-2015: a systematic analysis with implications for the sustainable development goals. Lancet Glob Health. 2017;5:e186-97. https://doi.org/10.1016/S2214-109X(16)30334-5.

6. Hussain LM, Redmond AD. Are pre-hospital deaths from accidental injury preventable? BMJ. 1994;308(6936):1077-80. https://doi.org/10.1136/bmj.308. 6936.1077.

7. Cole KA, Gable S. Protecting children from unintentional injuries. [Document on the Internet]. Springfield: University of Missouri; 2002. Updated 2011. Available from: http://extension.missouri.edu/p/GH6026.

8. World Health Organization. Injuries and violence: the facts. Geneva: World Health Organization; 2014.

9. Report on the Development of Maternal and Child Health in China (2019). http://www.nhc.gov.cn/fys/s7901/201905/bbd8e2134a7e47958c5c9ef032e1 dfa2.shtml.

10. Xiang $L$, Wang $K$, Miao $L$, et al. Injury-related mortality among children younger than 5 years in China during 2009-2016: an analysis from national surveillance system. Inj Prev. 2019;25(1). https://doi.org/10.1136/injuryprev2018-042853.

11. Yan S, Zhu X. Epidemiological study on the trend of accidental deaths among children under five in Beijing, during 2003-2012. Chinese J Epidemiol. 2014;35(5):562-5 (in Chinese).

12. Wang $L, G a o Y$, Yin $P$, et al. Under-five mortality from unintentional suffocation in China, 2006-2016. J Glob Health. 2019;9(1). https://doi.org/10. 7189/jogh.09-010602.

13. The Central Committee of the Communist Party of China, The State Council of the People's Republic of China. 'Healthy China 2030 planning outline', 2016. http://www.gov.cn/xinwen/2016-10/25/content_5124174.htm.

14. Gao Y, Schwebel DC, Hu G. Infant mortality due to unintentional suffocation among infants younger than 1 year in the United States, 1999-2015. JAMA Pediatr. 2018;172:388-90. https://doi.org/10.1001/jamapediatrics.2017.4887.

15. Pan SY, Ugnat AM, Semenciw R, et al. Trends in childhood injury mortality in Canada, 1979-2002. Inj Prev. 2006;12:155-60. https://doi.org/10.1136/ip. 2005.010561.

16. Tomashek KM, Hsia J, Iyasu S. Trends in postneonatal mortality attributable to injury, United States, 1988-1998. Pediatrics. 2003;111:1219-25.

17. Sekii H, Ohtsu T, Shirasawa T, et al. Childhood mortality due to unintentional injuries in Japan, 2000-2009. Int J Environ Res Public Health. 2013;10:528-40. https://doi.org/10.3390/ijerph10020528.

18. Bhalla $\mathrm{K}, \mathrm{Hu} \mathrm{G}$, Bake TD. Injuries among children: an unrecognized threat in low- and middle-income countries. 140st APHA Annual Meeting and Exposition 2012; 2012.

19. Mack KA, Rudd RA, Mickalide AD, et al. Fatal unintentional injuries in the home in the U.S. 2000-2008. Am J Prev Med. 2013;44(3):239-46. https://doi. org/10.1016/j.amepre.2012.10.022.

20. Statistical Information Center of the National Health and Family Planning Commission, National Center for Chronic and Non-communicable Disease 
Control and Prevention, Chinese Center for Disease Control and Prevention. The national death surveillance data sets [M]. Beijing: China Science and Technology Press; 2017.

21. Runyan CW, Casteel C, Perkis D, et al. Unintentional injuries in the home in the United States part I: mortality. Am J Prev Med. 2005;28:73-9. https://doi. org/10.1016/j.amepre.2004.09.010

22. Fatmi Z, Kazi A, Hadden WC, et al. Incidence and pattern of unintentional injuries and resulting disability among children under 5 years of age: results of the National Health Survey of Pakistan. Paediatr Perinat Epidemiol. 2009; 23(3):229-38. https://doi.org/10.1111/j.1365-3016.2009.01024.x.

23. Wang $Y$, He C, Li X, et al. Nationwide study of injury-related deaths among children aged 1-4 years in China, 2000-2008. J Paediatr Child Health. 2014; 50(10). https://doi.org/10.1111/j.1440-1754.2012.02525.x

24. Big data, a left-behind child in rural areas in 2018. 2018. http://hunan.voc. com.cn/xhn/article/201809/201809010824053615.html.

25. Yang $L$, Nong QQ, Li CL, et al. Risk factors for childhood drowning in rural regions of a developing country: a case-control study. Inj Prev. 2007;13(3): 178-82. https://doi.org/10.1136/ip.2006.013409.

26. Liu ZY, Kong FJ, Yin L, et al. Epidemiological characteristics and influencing factors of fatal drowning in children under 5 years old in Hunan Province, China: case-control study. BMC Public Health. 2019;19(1):955-62.

27. Jiang B, Liang S, Peng ZR, et al. Transport and public health in China: the road to a healthy future. Lancet. 2017;390(10104):1781-91. https://doi.org/ 10.1016/S0140-6736(17)31958-X

28. United Nations General Assembly. Transforming our world: the 2030 agenda for sustainable development [Z]. New York: United Nations; 2015. p. 14-27.

29. Wang SY, Li YH, Chi GB, et al. Injury-related fatalities in China: an underrecognised public-health problem. Lancet. 2008;15:372(9651). https://doi. org/10.1016/50140-6736(08)61367-7.

30. The state council of the People's Republic of China. National program of action for child development in China 2011. http://www.gov.cn/jrzg/201108/09/content_1921982.htm.

31. United States Center for Disease Control and Prevention. National Action Plan for Cllild Injury Prevention [M]. America. 2012.

32. Unintentional injuries: prevention strategies for under 15s. Public health guideline [PH29]. 2010. https://www.nice.org.uk/guidance/ph29.

33. Ribas Rde C, Tymchuk AJ, Ribas AF. Brazilian mothers' knowledge about home dangers and safety precautions: an initial evaluation. Soc Sci Med. 2006;63(7):1879-88. https://doi.org/10.1016/j.socscimed.2006.04.026.

34. Garstang J, Ellis C, Griffifiths F, et al. Unintentional asphyxia, SIDS, and medically explained deaths: a descriptive study of outcomes of child death review (CDR) investigations following sudden unexpected death in infancy. Forensic Sci Med Pathol. 2016;12(4). https://doi.org/10.1007/s12024-0169802-0.

35. Moon RY, Task force on sudden infant death syndrome. SIDS and other sleep-related infant deaths: updated 2016 recommendations for a safe infant sleeping environment. Pediatrics. 2016;138(5):e20162938. https://doi. org/10.1542/peds.2016-2940

\section{Publisher's Note}

Springer Nature remains neutral with regard to jurisdictional claims in published maps and institutional affiliations.

Ready to submit your research? Choose BMC and benefit from:

- fast, convenient online submission

- thorough peer review by experienced researchers in your field

- rapid publication on acceptance

- support for research data, including large and complex data types

- gold Open Access which fosters wider collaboration and increased citations

- maximum visibility for your research: over $100 \mathrm{M}$ website views per year

At $\mathrm{BMC}$, research is always in progress.

Learn more biomedcentral.com/submissions 